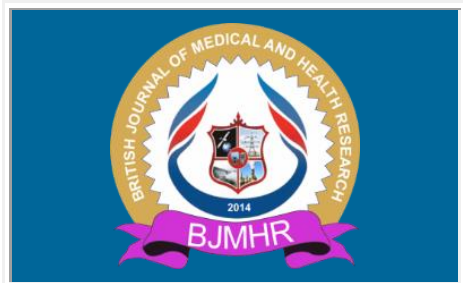

\title{
BJMHR
}

British Journal of Medical and Health Research

Journal home page: www.bjmhr.com

\section{A Histopathological Evaluation of Connective Tissue Stroma in Oral Squamous Cell Carcinoma: A Histochemical study}

\author{
Sarwar Hashmi ${ }^{1}$, Shahla Khan ${ }^{2 *}$, Hitesh $\mathbf{V i j}^{3}$ \\ 1. Dept. of OMFS, Dr. Z. A. dental college, AMU, aligarh. 202002 \\ 2. Dept of Oral \& Maxillofacial Pathology, IDST, Modinagar, UP. \\ 3.Consultant Dentist Boston, USA
}

\begin{abstract}
The aim of the study was to analyse and compare the nature of stromal collagen fibers in different grade of Oral Squamous Cell Carcinoma (OSCC) by using different connective tissue stains like Masson's Trichrome, Van Geison and Picrosirius stains and to understand the possible role of stroma in progression of OSCC. Total 44 cases of OSCC and 5 sections of controls were examined using three connective tissue special histochemical stains. In this study, we found a gradual change in polarizing colours of collagen fibers from orange red to yellowish green from well to poorly differentiated OSCC around the tumour islands. It was observed that stromal changes at the invading front of tumour islands and with the progression of neoplasm can be evaluated more efficiently with the use of Picrosirius stain, Masson Trichrome stain and van Geison stain
\end{abstract}

Keywords: Squamous Cell Carcinoma, Collagen, Picrosirius red stain, polarizing colours, Masson Trichrome stain, van Geison stain 


\section{INTRODUCTION}

The word 'carcinoma' is derived from the Greek word carcinos + oma meaning a malignant epithelial neoplasm that tends to invade the surrounding tissues and metastasize to distant regions of the body. ${ }^{1}$ Squamous cell carcinoma (SCC) is an epithelial malignancy that occurs in organs that are normally covered with squamous epithelium which includes several different anatomic sites, including the skin, lips, oral cavity, tongue, floor of mouth, oesophagus etc. represents the most common cancer capable of metastatic spread in worldwide. ${ }^{2}$

According to World Health Organization, Oral cancer holds the eighth position in the cancer incidence ranking worldwide, with epidemiologic variations between different geographic regions (It is the third most common malignancy in south-central Asia). WHO expects a worldwide rising Oral squamous cell carcinomas (OSCC) incidence in the next decades. ${ }^{3}$ squamous cell carcinoma (SCC) is considered the most frequent malignant neoplasm in the oral cavity and it predominantly affects Caucasian males with multifactorial etiology including DNA mutations. ${ }^{4,5,6,7}$

On the basis of established criteria OSCC is graded as well differentiated, moderately differentiated \& poorly differentiated, well differentiated OSCC closely resembles normal squamous epithelium. Moderately differentiated OSCC contains heightened mitotic activity, including abnormal mitoses and distinct nuclear pleomorphism and there is usually less keratinization. In poorly differentiated OSCC immature cells predominate with numerous typical and atypical mitoses and minimal keratinization. ${ }^{8}$

Connective tissue occurs in many different forms with diverse physical properties, loose connective tissue act as a biological packing material between cell and other tissues. Dense form of connective tissue provides tough physical support in the dermis of the skin. ${ }^{9}$ Collagen comprises one-third of the total protein of the body accounts for three-quarters of the dry weight of skin, and is the most prevalent component of the extracellular matrix (ECM). The ECM is a macromolecular network with both structural and regulatory functions. The most copious protein in the ECM is members of collagen family. ${ }^{10}$

The mature ECM consists of a supramolecular aggregate of connective tissue proteins, including fibrillar and non-fibrillar collagens, elastin, glycoproteins and glycosaminoglycans, which interact with one another through covalent and non-covalent bonds to form highly insoluble materials. ${ }^{11}$ Extracellular Matrix molecules influence differentiation, proliferation and migration of epithelial tumor cells; and also have stabilizing and separating functions. The extracellular microenvironment of tumors is determined by matrix synthesized by normal and tumor cells, as well as the host stromal components secreted by surrounding host fibroblasts. 12 
Stromal elements surrounding the tumor (Tumor stroma), which includes inflammatory cells, endothelial cells and fibroblasts, play a very important role in tumor progression as stated throughout the literature. Stroma consisting of myofibroblast-driven reaction, predominantly contains fibrillar collagens (types I and III), are stated to be a poor prognostic indicator. ${ }^{13} \mathrm{ECM}$ provides the vascular supply, nourishment, oxygen supply, and also limits the influx of inflammatory cells, thereby acting as a barrier for immunological rejection. ${ }^{14}$

For evaluating inflammatory cell component in different grades of OSCC, the predominant cell type was lymphocytes. Well-differentiated group had highest inflammatory cell count when compared to moderately and poorly differentiated groups. Immune cells of the host react to OSCC by promoting lymphocytic infiltration. ${ }^{15,16}$ However, immune cell functions may be compromised by OSCC cells. Signaling abnormalities, spontaneous apoptosis, reduced proliferation and function of circulating dendritic cells, tumor-infiltrating lymphocytes, T-cells, and natural killer cells have been detected in oral cancer patients. Immunosuppressive actions are believed to be mediated by both soluble factors and contact-mediated factors of the cancer cells, which inhibit normal functioning of immune cells and promote cancer growth and progression.

There is sufficient evidence in the literature that inflammatory cells, particularly lymphocytes modify the nature of stroma by releasing lymphokines that regulate the biosynthesis of collagen and proliferation of fibroblasts. Mononuclear cells (MNL), when they are activated by inflammatory stimulus, produce various inhibitory and stimulatory regulatory mediators. ${ }^{17}$ Therefore, we would like to link our observation of thicker collagen fibers in welldifferentiated OSCC, which also showed high count of lymphocytes, to increased production of stimulatory mediators by these mononuclear inflammatory cells. The thinner fibers associated with poorly differentiated cases indicate lack of stimulatory effects due to significantly less number of inflammatory cells and may also be due to the production of proliferation inhibitory lymphokines by the available cells. At the same time, role of tumor cells in modulating the stroma also cannot be neglected. It is possible that in poorly differentiated cases, the tumor cells are least differentiated and highly aggressive and aberrant in behavior which may also be reflected in increased production of destructive enzymes that can modify the collagenous component of microenvironment while this may not be a prominent feature in well-differentiated cases, as the tumor cells are well differentiated and less aggressive.

Studies have shown an increase in Oxytalan, elaunin, elastic fibers and decrease in collagen fibers with some transformation changes associated with OSCC and lymph node metastasis by using verhoff van Geison stain. ${ }^{18,19,20,21}$ Various studies undertaken on evaluation of collagen in different grades of OSCC using the PCR stain and observed a gradual change of polarization 
colours of collagenous stroma surrounding the tumour cells, from reddish-orange to greenishyellow as it progresses from well to poorly differentiated. ${ }^{18,19,20,22}$ The colour changes observed in these studies clearly indicate some alterations in the stromal tissue around the tumour cells, which in turn indicates the contribution of the stromal constituents in the progression of the neoplasm.

Thus in the current study an attempt has been made to examine and evaluate the colour changes of the stromal tissue around tumour cells in OSCC. This was done in order to understand the progression of OSCC and assess its prognosis.

\section{MATERIALS AND METHOD}

The material for the present study included, 44 formalin fixed paraffin embedded tissue blocks comprising of histopathologically diagnosed cases of well differentiated ${ }^{15}$, moderately differentiated ${ }^{15}$, poorly differentiated OSCC ${ }^{9}$, and control group (normal buccal mucosa) ${ }^{5}$, retrieved from the archive of the Department of Oral Maxillofacial Pathology and Microbiology, IDST, Kadrabad, Department of Oral and Maxillofacial Surgery Dr ZA Dental college, AMU Aligarh, and Department of Otolaryngology, King Georges Medical University, Lucknow.

Paraffin embedded tissue blocks were sectioned at 4 um thickness, three sections were obtained from each block. The sections were floated on to the micro slides and incubated at $47^{\circ} \mathrm{C}$ on slide warmer for 1 hour for ensuring adhesion of the sections to the slide. Sections were then deparaffinized in xylene and hydrated through decreasing grades of alcohol and taken to water. The slides from each block were then stained with H\&E, Masson's Trichrome, van Gieson, and Picrosirius Red stain (Figure 1a, 1b, 1c, \& 1d).

The sections were examined with a polarising microscope. Change in the birefringence of collagen fibers was noted under polarizing microscope in each tissue section stained with Picrosirius Red stain. The sections stained with Masson's Trichrome \& van Gieson were studied under normal light microscope to evaluate if there was any difference in the staining pattern of the connective tissue in different grades of oral squamous cell carcinoma as compared to the control.

The result were analyzed using SPSS-16 whereas ANOVA test is applied for comparison of difference between mean values of more than two groups.

\section{RESULTS AND DISCUSSION}

All the cases were diagnosed using haematoxylin \& eosin staining and 5 tissues of normal oral mucosa were used as controls (Figure $2 \mathrm{a}, 2 \mathrm{~b} \& 2 \mathrm{c}$ ). In this study Thin and thick (50 each) collagen fibres were counted in the stroma and difference in their birefringence were observed using a polarizing microscope at 100X magnification under oil immersion in each tissue section 
stained with Picrosirius Red stain. The sections stained with Masson's Trichrome \& van Gieson were studied under normal light microscope to evaluate the difference in the staining intensity of the connective tissue in between mild, moderate and poorly differentiated OSCC and the control.

We observed in our study that 5 controls from normal buccal mucosa stained with Picrosirius red stain (Figure1d) showed predominantly reddish or yellowish orange birefringence. (Graph 1\&2) In the three grades of SCC which were studied, the collagen fibres in well-differentiated SCC (Fig. 3c) predominantly revealed reddish orange to yellowish orange birefringence in the connective tissue. A gradual change in the polarizing colours from yellowish orange to greenish yellow was observed in moderately differentiated SCC (Figure 4c), However, in poorly differentiated SCC, predominantly greenish yellow polarizing colour with weak birefringence was observed (Figure 5c).

All the tissue sections stained with Masson's Trichrome \& van Gieson stain were observed under Light Microscope and qualitatively evaluated and graded depending on the staining intensity.The different patterns of response are: Normal staining (+) as seen in Control Mild staining (++),Moderate staining (+++), Intense (++++). All the control group stained with Van Giesen and Masson trichrome stains showed normal staining (+) (Figure 1b \& 1c), In cases of well differentiated squamous cell carcinoma out of 15,14 cases showed mild staining $(++)$ with the both stains (Figure 3a \& 3b). In cases of moderately differentiated squamous cell carcinoma out of 15,14 cases showed moderate staining (+++) with the both stains (Figure $4 \mathrm{a} \& 4 \mathrm{~b})$. In cases of poorly differentiated squamous cell carcinoma all 9 cases showed intense staining with both the stains (Figure 5a \& 5b).

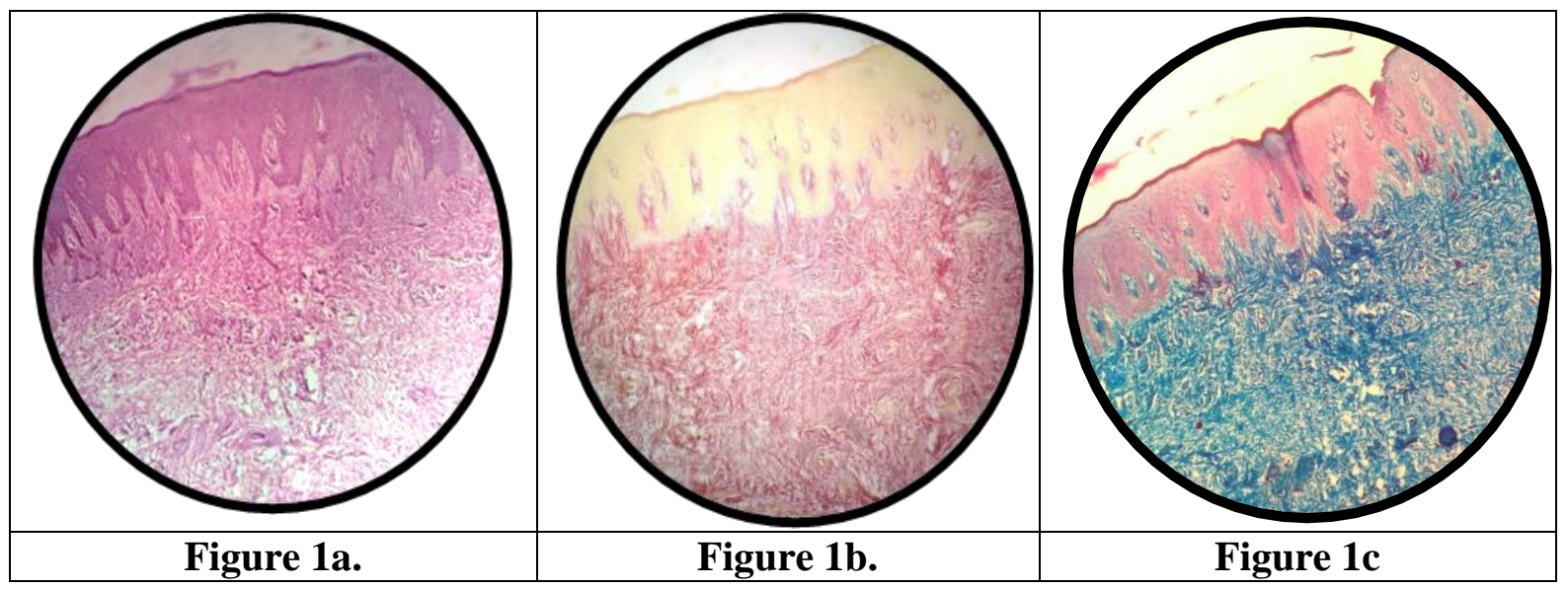




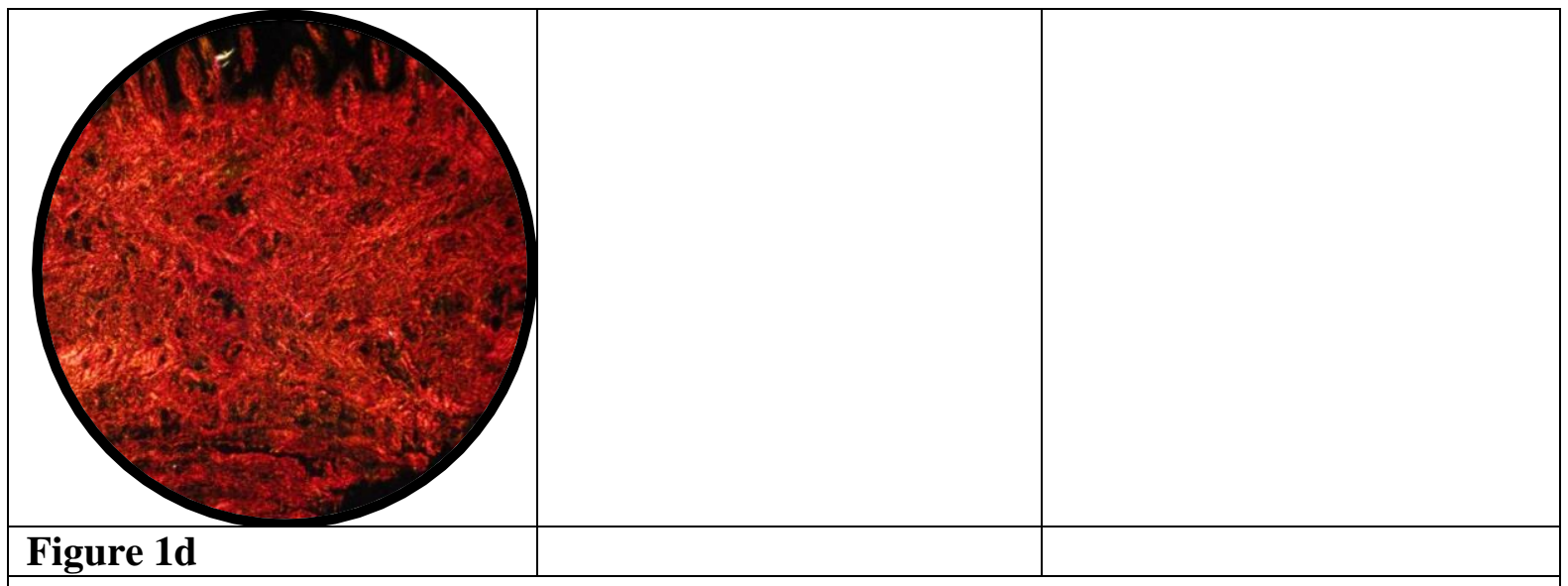

Figure 1: Photomicrograph showing normal buccal mucosa section stained with (1a) H\&E stain, (1b) van Gieson stain, (1c) Masson trichrome stain, (1d) Picrosirius red stain

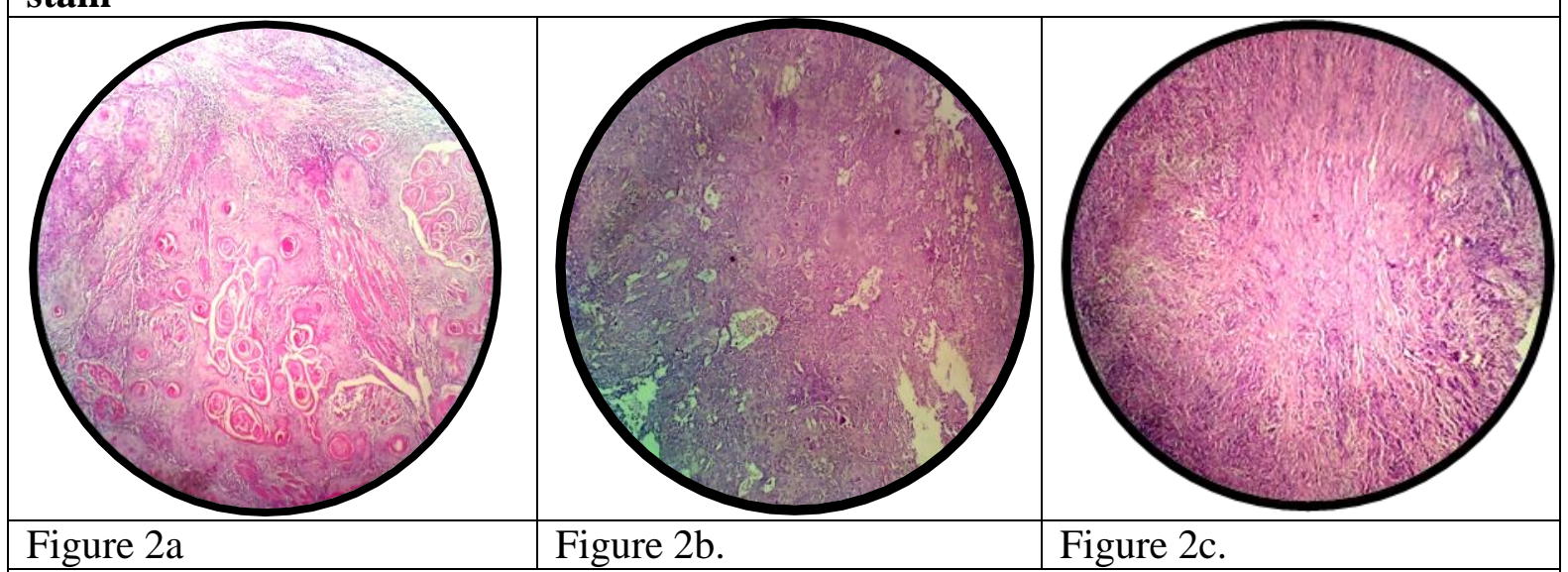

Figure 2:Photomicrograph of H\&E stained sections of Well differentiated OSCC (2a), Moderately differentiated OSCC (2b), \& poorly differentiated OSCC (2c)

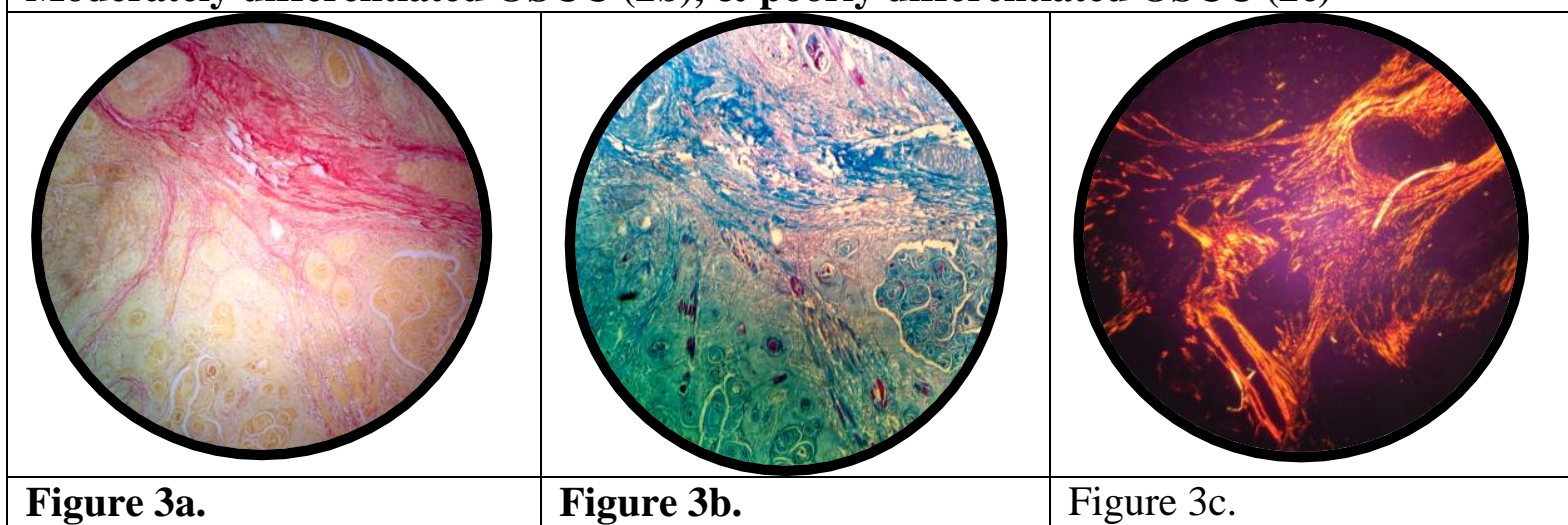

Figure 3: Photomicrograph of Well differentiated OSCC section stained with Van Gieson (3a), Masson trichrome stain (3b) \& Picrosirius red stain under polarizing microscope (3c)

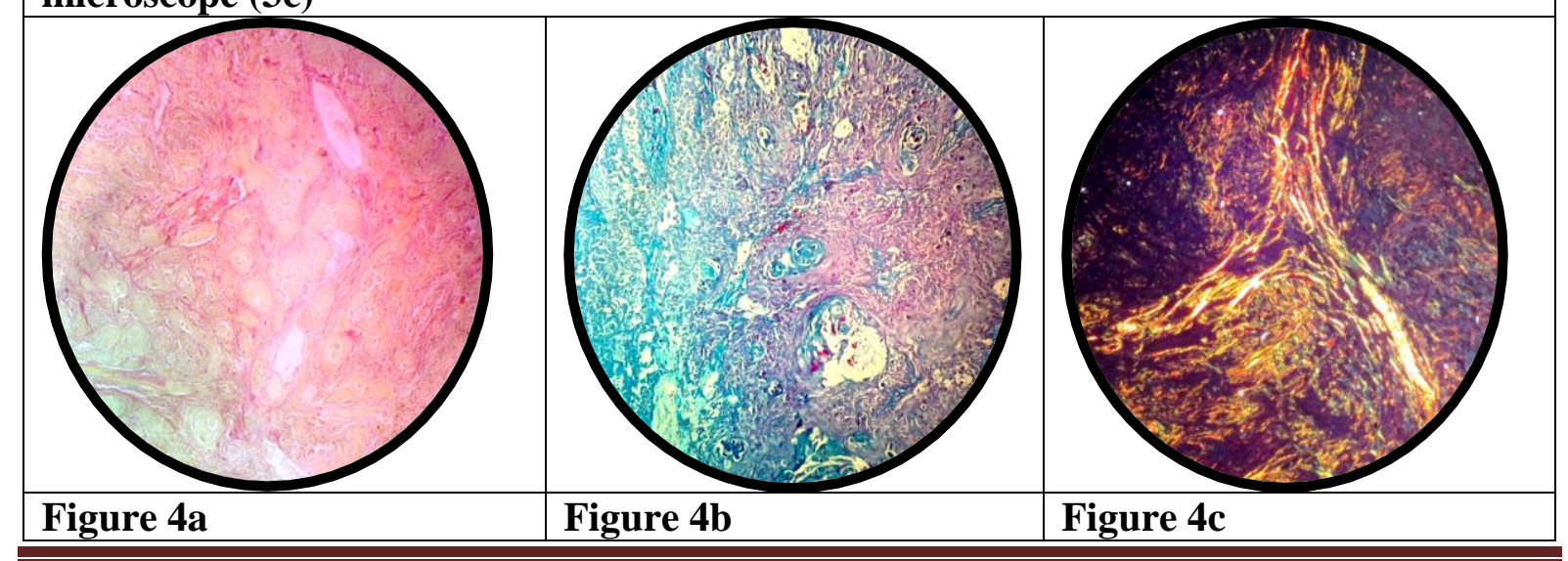




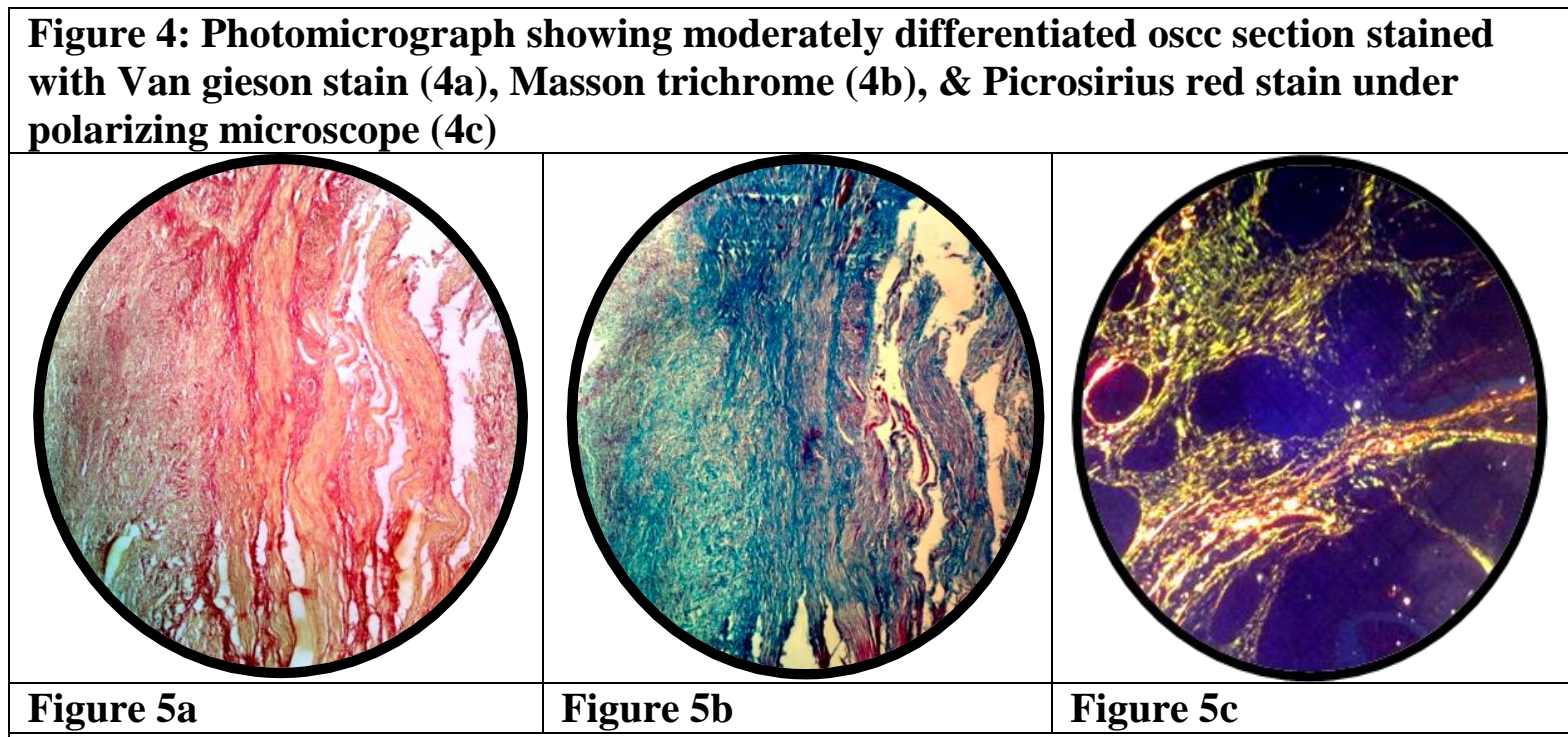

Figure 5: Photomicrograph showing poorly differentiated osce section stained with Van Gieson stain (5a), Masson trichrome stain (5b), \& PSR under Polarizing microscope (5c)

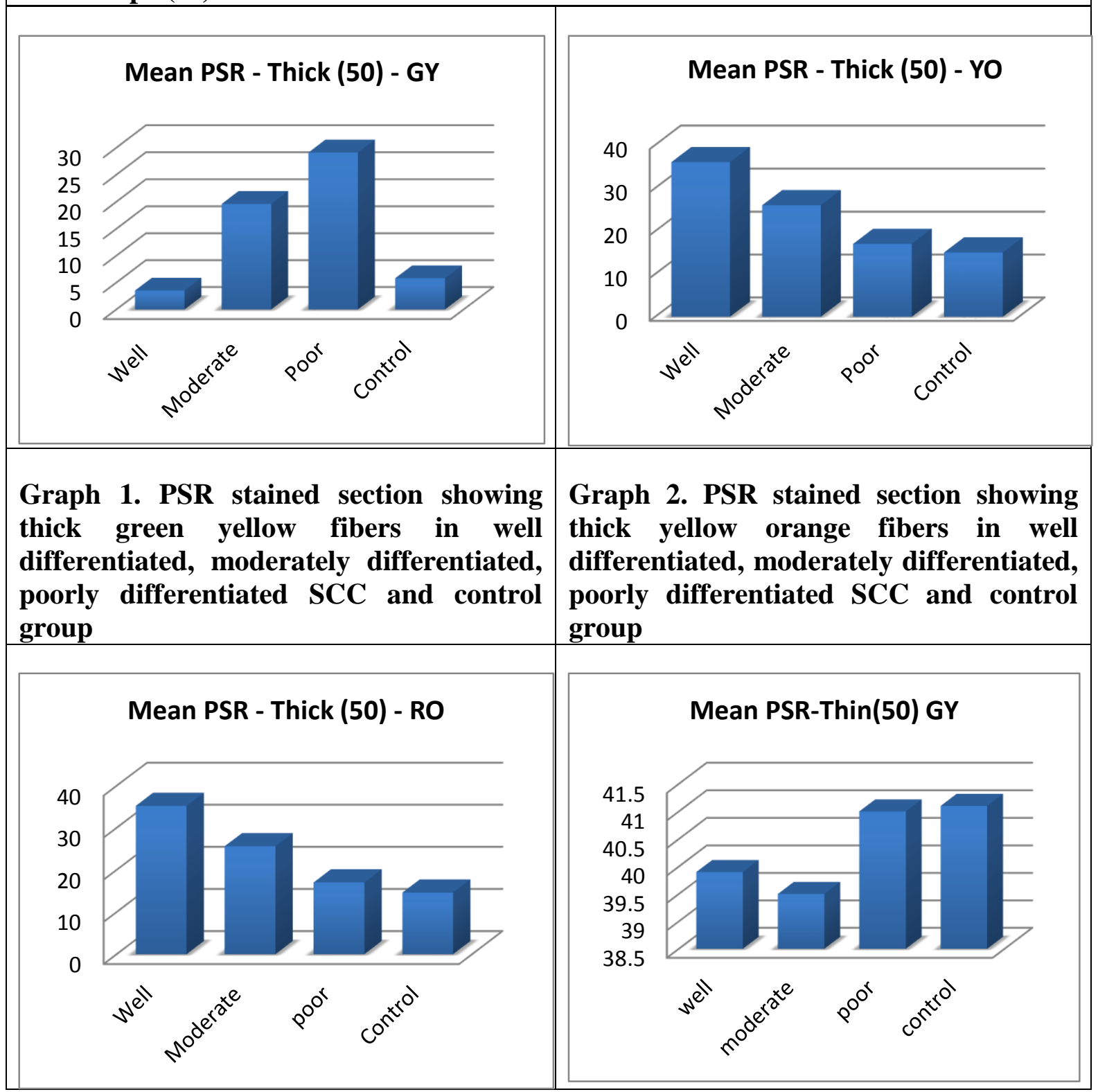




\section{Graph 3. PSR stained section showing thick red orange fibers in well differentiated, moderately differentiated, poorly differentiated SCC and control group.}

Graph 4. PSR stained section showing thin green yellow fibers in well differentiated, moderately differentiated, poorly differentiated SCC and control group.
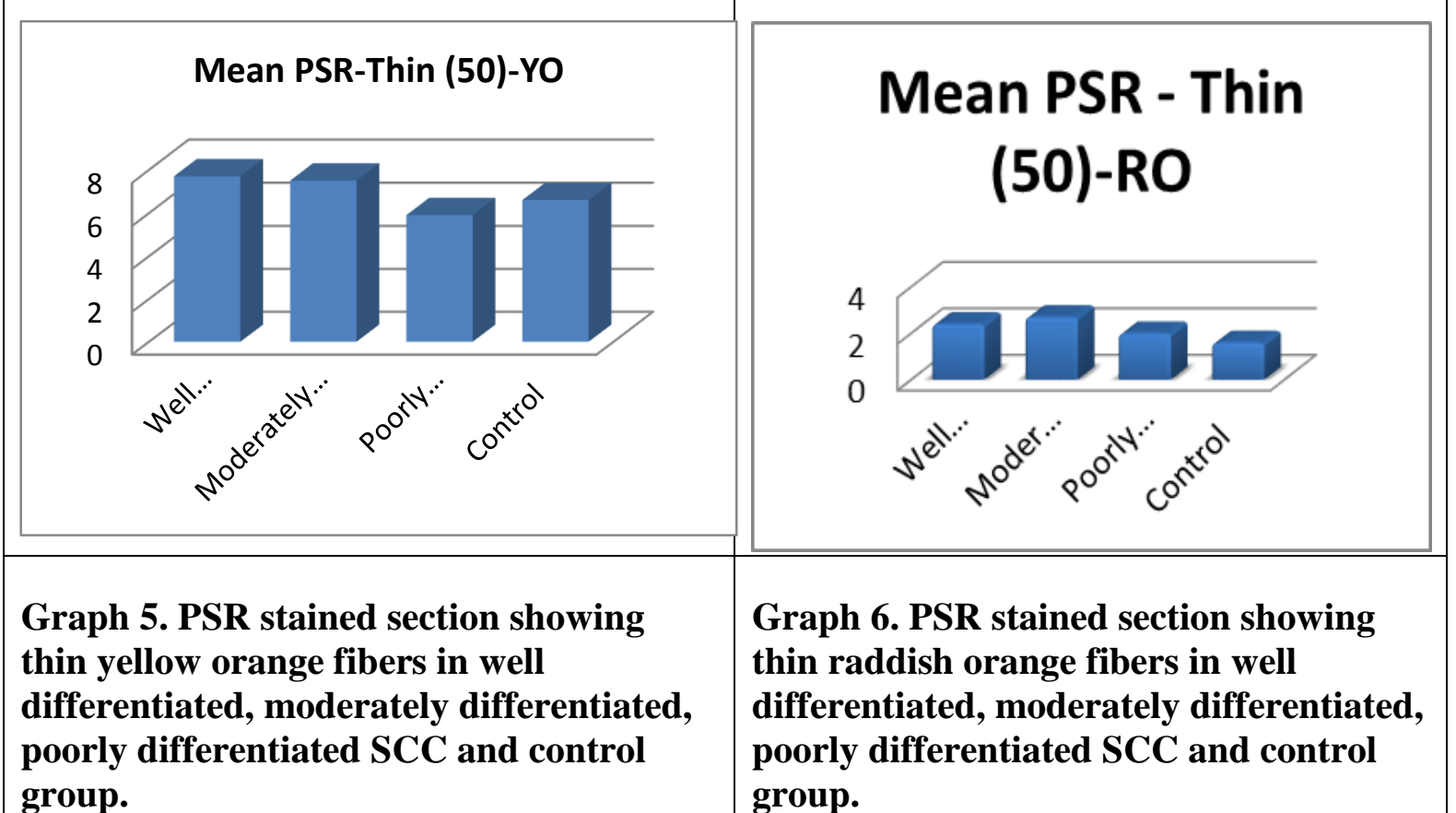

Graph 5. PSR stained section showing thin yellow orange fibers in well differentiated, moderately differentiated, poorly differentiated SCC and control group. group.

\section{DISCUSSION}

Carcinomas are characterized by invasion of malignant cells into the underlying connective tissue and migration of malignant cells to form metastases at distant sites. These processes require alterations in cell-cell and cell-extracellular matrix (ECM) interactions. ${ }^{23}$ Cell interactions with ECM are important to pathological changes that occur during cell transformation and tumoregenesis. ${ }^{24}$ Neoplastic invasion and metastases are characterized by the ability of tumor cells to cross tissue compartment boundaries. The subepithelial basement membrane plays an important role in the complex interactions of this process, as it is the first barrier to be traversed by the neoplastic cells. ${ }^{23}$

Recent studies suggest that tumor stroma is associated with tumor progression. Endothelial cells, pericytes, inflammatory cells, fibroblasts and extracellular matrix constitute the tumor microenvironment which helps in tumor growth, invasion and metastasis. ${ }^{25,26}$ Tumor stroma is essential for the growth and development of cancer tissue. It acts as a medium for exchange of nutrition, gases, waste products and also limits the exposure of the tumors cells to the immune system. ${ }^{22,27}$ Cancer cells show genetic alterations which may influence the adjacent connective tissue enabling the growth, invasion and sustenance of these malignant cells. ${ }^{23}$

Collagen is a chief component of extracellular matrix, plays a vital role in maintenance of structural integrity and tissue function of the body ${ }^{22}$ and has many known types. ${ }^{28}$ In normal 
oral mucosa significant amount of Type III collagen is seen in sub epithelial region and Type I and II are seen more in the deeper areas of the connective tissue. In cases of carcinoma Type I collagen fibers are seen surrounding the tumor islands. These areas were observed in the current study.

Various studies suggests that collagen changes are seen as the malignancy progresses $22,23,25,27$ and in our study we also observed similar results where collagen changes were obvious in well differentiated squamous cell carcinoma, moderately differentiated squamous cell carcinoma and poorly differentiated squamous cell carcinoma.

Routine Haematoxylin \& Eosin staining cannot recognize the nature and changes in collagen, so special stains like the Trichrome stains e.g. Masson's trichrome and van Gieson are used and we observed that there were gradual change in the intensity of Masson's trichrome (Fig. 3b, 4b \& 5b) and van Gieson staining (Figure 3a, 4a \& 5a) from well to moderate \& from moderate to poorly differentiated squamous cell carcinoma respectively.

Collagen is an anisotropic structure, which exhibits the phenomenon of birefringence, due to the arrangement of the collagen molecules. ${ }^{29}$ These collagenous molecules strongly reacts with acidic dyes like Sirius Red resulting in the enhancement of their natural birefringence. ${ }^{30}$ Different colors of birefringence are noticed in the different type of collagen. Picrosirius Red stain can show the nature of collagen, due to its ability to detect thin fibers. It can also differentiate between mature, immature and pathological fibers. ${ }^{31}$

Type I collagen forms thick bands, composed of closely packed thick fibres and has an intense reddish-orange birefringence (Figure 3c)). Type III fibers form thinner bands, composed of loosely disposed thin fibrils, having less intense birefringence and are green-yellow in color. ${ }^{30}$ (Figure 4c)).

Newly formed Type I collagen fibers also show a weak or less intense birefringence of greenyellow color which is similar to mature Type III fibers. These immature fibers become redorange only after maturing (undergoing cross-linking). Szendroi et al ${ }^{32}$ in 1983 did a study and observed that polarizing light technique is helpful to predict fibrotic process early, and supports above findings.

On comparing the thick fibers in Picrosirius Red stained sections of well differentiated squamous cell carcinoma with moderately differentiated squamous cell Carcinoma and poorly differentiated squamous cell carcinoma we observed highly significant results ( $p$-value $=0,000$ ) ( Graph 1). There was a significant increase in green-yellow fibers in moderately differentiated carcinoma and poorly differentiated carcinoma to well differentiated carcinoma( $p$-value 0,000 ) (Figure 3c, 4c \& 5c)). This may indicate the changes in the extracellular matrix due to the invasion of the tumor. In comparison there was a significant decrease in the yellow-orange fibers in moderately differentiated carcinoma and poorly differentiated carcinoma to well 
differentiated carcinoma( $\mathrm{p}$ - value 0,000) (Figure 3c, 4c, 5c). We also observed significant increase in reddish orange fibres in well differentiated carcinoma around the tumor islands in majority of fields, in comparison to moderately differentiated \& poorly differentiated carcinoma ( p- value 0,000) (Graph 3.)

The comparison of well differentiated squamous cell carcinoma with the control tissue yielded highly significant results which shown in benign nature of lesions there must be significant change in the collagen nature of their extracellular matrix.

These results were in accordance to the study done by Kalele PK et.al. ${ }^{22}$ Further on comparing the thick green-yellow and yellow-orange fibers of moderately differentiated squamous cell Carcinoma with those of poorly differentiated squamous cell Carcinoma the results were highly significant $(\mathrm{P}=0.000)$ (Graph $1 \& 2)$. This also is in accordance to the results obtained by Aparna et al, ${ }^{27}$ where they showed presence of more green-yellow thick fibers as compared to yellow-orange as the grade of OSCC moved from moderately to poorly differentiated Oral Squamous Cell Carcinoma.

In our study on comparing Picrosirius Red sections of Well Differentiated Squamous cell carcinoma with moderately differentiated squamous cell carcinoma and poorly differentiated squamous cell carcinoma, we observed that there was no significant change in the amount of thin fibers of all colours. (Graph 4, $5 \& 6$ )). This observation is similar to study carried out by Allon I et al. ${ }^{33}$ where they observed no sign of difference in staining of thin fibers with Picrosirius Red in well differentiated, moderately differentiated and poorly differentiated squamous cell carcinoma.

We observed in our study gradual changes in the collagen fibers birefringence and staining intensity in various grades of oral squamous cell carcinoma. The grading of OSCC (Well, moderate $\&$ poor) will also inform us the status of the tumor, possible management $\&$ prognosis. Special stains can improve usefulness in determining the aggressiveness of the lesion. Epithelial-mesenchymal interactions are said to cause breakdown of the collagen fibers and creation of an extracellular matrix environment conducive to the growth and metastasis of the tumor cells. This breakdown or degradation can be assessed by the intense staining and enhanced birefringence of collagen obtained using Masson trichrome and van Gieson and Picrosirius Red stains

Current diagnostic modalities like immunohistochemistery are favourite in laboratories around the world but in comparison to that, special stains like Picrosirius Red, van Gieson and Masson trichrome are not only cheaper but are also easier to do and replicate, making them more practical to use. Studies on squamous cell carcinoma using special stains are few and more studies with a larger sample size are needed to be done in different grades of squamous cell 
carcinoma, to get a better picture of the connective tissue changes seen. This in turn will lead to better treatment $\&$ hence better prognosis.

\section{REFERENCES}

1. The History of Cancer. Centre of oncology, Jules Bordet Institute Brusseles 2010; 1119.

2. Marinkovich MP. Tumour microenvironment: laminin 332 in squamous-cell carcinoma. Nat Rev Cancer 2007; 7:370-380.

3. World Health Organization. The World Oral Health Report 2003. Geneva: World Health Organization; 2003;6-7.

4. Hirota, S. K. et al. Risk factors for oral squamous cell carcinoma in young and older Brazilian patients: a comparative analysis. Med Oral Patol Oral Cir Bucal 2008;13(4):227-31

5. Wynder EL, Bross IJ. Aetiological factors in mouth cancer. Bri Med J 1957;18:113743

6. Ferreira FV, Nedel F, Etges A, Gomes APN, Fususe C, Tarquinio SBC. Etiologic factor associated with oral squamous cell carcinoma in non-smokers and non-alcoholic drinkers: A brief approach. Braz Dent J. 2012;23(5):586-90

7. Warnakulasurya S . Causes of oral cancer- a appraisal of controversies Br Dental Journal 2009; 207(10); 471-75.

8. Fang KH, Huang KK, Hui M, Chang YL, Histological differentiation of primary oral squamous cell carcinoma in an area of betel quid chewing prevalence. Am academy of otolaryngol 2009;141:743-49

9. Young B, Heath JW. Wheater's functional histology. Elsevier, 2000; 4:65.

10. Tresoldi I, Oliva F, Benvenuto F, Fantini M, Masuelli L, Bei R, Modesti I, Tendon's ultrastructure. Muscles Ligaments Tendons J 2013;3(1): 2-6.

11. Zucker S, Cao J, Malloy CJ. Role of matrix metalloproteinases and plasminogen activators in cancer invasion and metastasis: Therapeutic strategies. In: Baguley BC, Kerr DJ, editors. Anticancer drug development. Acedemic Press, San Diego 2002;1:92.

12. Kosmehl H, Berndt A, Katenkamp D. Molecular variants of fibronectin and laminin: Structure, physiological occurrence and histopathological aspects. Virchows Arch 1996; 429:311-22.

13. De Wever O, Demetter P, Mareel M, Bracke M. Stromal myofibroblasts are drivers of invasive cancer growth. Int J Cancer 2008; 123:2229-38. 
14. Venigella A, Charu S. Evaluation of collagen in different grades of oral squamous cell carcinoma by using the picrosirius red stain: A histochemical study. J Clin Diagn Res 2010; 4:3444-9.

15. Jewett A, Head C, Cacalano NA. Emerging mechanisms of immunosuppression in oral cancers. J Dent Res 2006;85:1061-73

16. Stephens M, Lim K, Stephens P, Thomas DW, Lim SH. Molecular characterisation of tumour infiltrating lymphocytes in oral squamous cell carcinoma. Cancer Immunol Immunother 1998; 46:34-40.

17. Duncan MR, Perlish JS, Fleischmajer R. Lymphokine/monokine inhibition of fibroblast proliferation and collagen production: Role in Progressive Systemic Sclerosis (PSS). J Invest Dermatol 1984;83:377-84

18. Thomas CL, Taber's Cyclopedic Medical Dictionary. Philadelphia 1989; 4:65.

19. Stevens A, Bancroft JD, Stevens A, eds. Theory and practice of histological technique. Edinburge churchil Livingstone 1990; 302.

20. Tiniford M Progress in the Development of Microscopical Techniques for Diagnostic Pathology J Histotechnol. 2009;32 (1): 9-19

21. Silveira NJ, Varuzza L, Machado-Lima A, Lauretto MS, Pinheiro DG, Rodrigues RV, Severino P, Nobrega FG, Silva WA, Jr., de BPCA, Tajara EH. Searching for molecular markers in head and neck squamous cell carcinomas (HNSCC) by statistical and bioinformatic analysis of larynx-derived SAGE libraries. BMC Med Genomics $2008 ; 1: 56$

22. Kalele KP, Managoli AN, Roopa MN, Kulkarni M, Bagul N, Kheur S. Assessment of collagen fiber nature, spatial distribution, hue and its correlation with invasion and metastasis in oral squamous cell carcinoma and surgical margins using Picro Sirius Red and polarized microscope. J Dent Res Rev. 2014; 1(1): 14-17.

23. Manjunatha BS, Agarwar A, Shah V. Histopathological evaluation of collagen fibers using picrosirius red stain and polarizing microscopy in oral squamous cell carcinoma. J of Cancer Res The 2015;11:272-76

24. L.Liaw and H.C. Crawford. Functions of the extracellular matrix and matrix degrading proteases during tumor progression. Braz J Med Biol Res 1999;32(7): 805-812

25. Goerge J, Narang R S, Rao NN. Stromal response in different histological grade of oral squamous cell carcinoma: A histochemical study. Indian J Dent Res 2012;23(6)

26. Yves A. De Clerck, Arthur M. Mercurio, M. Sharon Stack, Harold A. Chapman, Mary M. Zutter,Ruth J. Muschel, Avraham Raz, Lynn M. Matrisian, Bonnie F. Sloane, Agnes Noel, Mary J. Hendrix, Lisa Coussens, and Martin Padarathsingh Proteases, Extracellular Matrix, and Cancer. Am J Pathol 2004; 164(4): 1131-1139 
27. Venigella A, S Charu . Evaluation of collagen in different grades of oral squamous cell carcinoma by using the Picrosirius red stain- a histochemical study. J Clin Diag Res 2010;4:3444-3449.

28. Huang DK, Zhang YX, Man SQ, Yu FZ, Shen JJ. Comparison of collagen fiber staining between Van-Gieson staining and Masson trichrome staining of hepatic specimens in mice with Schistosoma japonicum infection, Chinese J Schistosomiasis control 2012;24(4):468-70.

29. Aarti M. Mahajan, Mahendra C. Mahajan, S. M. Ganvir, V. K. Hazarey The role of stroma in the expansion of odontogenic cysts and adenomatoid odontogenic tumor: A polarized microscopy study. J Nat Sci Biol Med 2013;(2)316-320

30. Montes \& Junqueira. The use ofpicprosirius-polarization method for the study of the biopathology of collagen. Mem Inst Cruz Rio de Jeneiro 1991;86:1-11

31. Haq M E U, Abid H, Hanif M K, Warraich R A, Mahmood H S, Siddique K. Frequency and pattern of Oral \& Maxillofacial carcinomas. Annals Vol. 2009;15(4):171-75

32. Singh $M$ et. al Morphometric analysis in potentially malignant head and neck lesion oral submucous fibrosis. Asian Pac J Cancer prev 2010;11:257-260

33. Tresoldi I, Oliva F, Benvenuto F, Fantini M, Masuelli L, Bei R, Modesti I, Tendon's ultrastructure. Muscles Ligaments Tendons J 2013;3(1): 2-6.

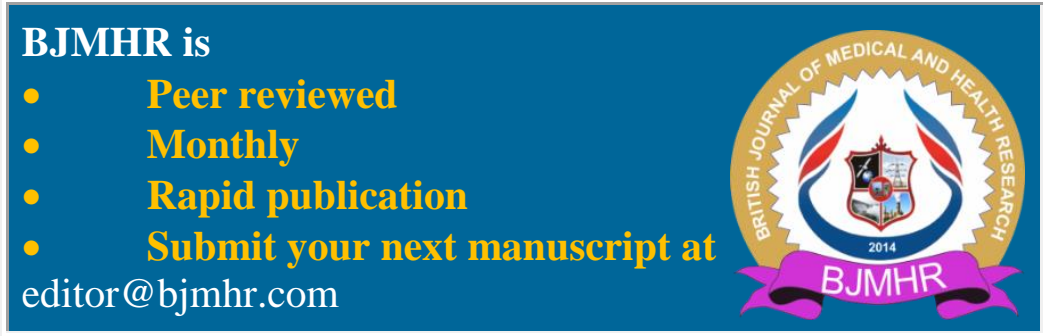

